\title{
PROSPECTS FOR THE PROGRESS OF HETERODOX ECONOMICS
}

\author{
Sheila C Dow
}

A contribution to a Roundtable discussion on The Progress of Heterodox Economics at the Annual HES Conference, Greensboro NC, 25-28 June, 1999. Published in Journal of the History of Economic Thought, 22(2):157-70, 2000.

\begin{abstract}
While progress in orthodox economics is understood as an internal concept, progress in heterodox economics has both an internal and external dimension, where the latter refers to persuasive success. This broader understanding of progress reflects the fundamental, methodological level at which we distinguish between orthodox and heterodox economics. Regarding internal progress, orthodox economics retains cohesion at the level of formalism, but this cohesion is showing strains because of the inevitable limitations imposed by formalism. While more apparently disparate, heterodox economics can be seen to be more methodologically cohesive; this is explained in terms of a qualified form of pluralism at a range of levels. A discussion of progress of ideas in terms of persuasion (with sociological and institutional, as well as linguistic, dimensions) provides the basis for a considering a pluralist strategy for promoting the progress of heterodox economics.
\end{abstract}

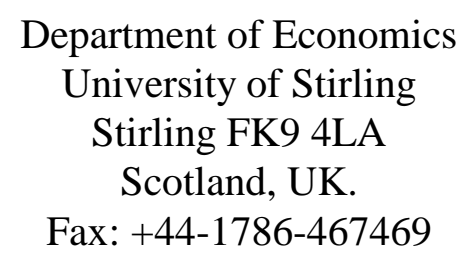


Prospects for the Progress of Heterodox Economics

e-mail: s.c.dow@stir.ac.uk

Second draft, August 1999 


\section{Introduction}

What are the prospects for progress in heterodox economics? Orthodox economists are concerned with progress, but the progress of economics per se, which is generally identified with orthodox economics itself. Further, progress is regarded as a natural feature of scientific activity, and is broadly unidirectional; the important issue is the speed of progress rather than its presence. There may be dispute as to the criteria for identifying progress, but in principle it should be possible to agree on a set of criteria.

But, for heterodox economics, progress is not only a matter of progress within heterodox economics, is also a relative concept - in particular relative to orthodox economics. Thus, while heterodox economists have established criteria by which to assess progress internal to heterodox economics, there is also the external issue of how far the overall approach is persuasive relative to orthodox economics. This frame of reference colours the whole notion of what constitutes progress; since heterodox economists cannot but be aware of alternative approaches (notably the orthodoxy) there is a greater consciousness of the absence of absolute grounds for assessing progress. For orthodox economists unaware (wilfully or otherwise) of alternatives, there is a more natural tendency to consider progress in terms of set criteria applied to a particular understanding of what constitutes economics.

The dualism of orthodoxy-heterodoxy carries its own dangers (see Dow, 1990); there are grey areas in between which we will want to explore as being important for the dynamics of the development of economics in general. But for the time being we proceed with the dual. Thus, disregarding for the moment the exceptions to the rule, we consider first in more detail what we mean by the progress of orthodox economics, and then of heterodox economics. It is important to take the time to consider the substance behind the terms 'progress', 'orthodox' and 'heterodox' since that is what also lies behind the prospects for progress in the future, and the strategies to be adopted to ensure progress in heterodox economics, which we discuss in the fourth section.

The argument to be developed below will rest on the use of a methodological distinction between orthodox and heterodox economics, namely the distinction between a closed-system approach and an open-system approach. Put simply, a closed system-approach presumes that all relevant variables and relationships between variables are knowable, and thus amenable to representation by a single formal mathematical system. An open-system approach rather sees the subject matter evolving such that not all relevant variables and relationships are knowable. Knowledge is thus built up by means of partial systems using methods which are not commensurate enough for representation by means of a formal mathematical system. ${ }^{1}$ I have in mind as heterodox economics a collection of non-orthodox schools of thought such as Post Keynesian economics, institutionalist economics, neo-Austrian economics, behavioural economics, social economics, feminist economics and Marxian/radical economics, all of which employ some form of open-system approach.

We consider orthodox economics first, in terms of its internal criteria for progress, and how these criteria constrain the understanding of progress. Because the external dimension (and thus the role of persuasion) is precluded by orthodox methodology, the impression can be created that the orthodox criteria for progress have some universal validity. The broader understanding of progress in heterodox

\footnotetext{
${ }^{1}$ For a fuller discussion of the distinction between closed and open systems, see Lawson (1997).
} 
economics is then considered in section three, where internal criteria for progress are understood to hold only within the relevant paradigm (and this is how the orthodox criteria for progress too are understood). The emphasis in the discussion however is put on progress according to the (external) criterion of persuasive success. This suggests a different kind of strategy for progress than is implied by internal criteria. Consistent with the (qualified) pluralist content of heterodox methodology, a (qualified) pluralist strategy is suggested in section four. By focusing on the practical question of how to increase the persuasiveness of heterodox economics, it is hoped that the significance of external progress is made more clear.

\section{The Progress of Orthodox Economics}

Classifying the orthodoxy in terms of content is becoming increasingly difficult. Some years ago it would be reasonable to see equilibrium, and even general equilibrium, as the organising concept which unified the orthodoxy (see Weintraub, 1985; Hausman, 1992). Then orthodox economics could be identified as collections of partial and general analyses all addressed to the goal of establishing a complete general equilibrium system. Further, insofar as methodology was discussed, there was agreement that progress could be identified in terms of some form of empirical success, ${ }^{2}$ or, in the case of pure theory, that the scope of the theory was continually being extended with a view ultimately to empirical testing. ${ }^{3}$

But there has been a notable fragmentation in the content of orthodox economics such that general equilibrium theory is only one framework among many (see Dow, 1997a; Coats, 1998; Hodgson, 1999). Game theory for example does not contribute directly to the general equilibrium project; experimental economics questions the specification of rational behaviour; and so on. Further there has been a questioning particularly within New Classical economics of the capacity for policy advice, and thus of policy itself, given information limitations. Indeed, while rational expectations is now a conventional modelling assumption, the rational expectations research project itself has run into difficulties. This has followed on the realisation that taking account of anything approaching the real diversity of information sets raises the prospect of multiple equilibria. This is an interesting outcome of a genuine attempt to overcome the pure/applied divide by means of assuming that observed states were equilibrium states in the sense that they reflected rational choice. As Hahn (1983) has argued in relation to the rational expectations approach, it is not yet time for the scaffolding of unrealistic modelling assumptions to come down.

So the long-standing divide between pure and applied work persists. But the fragmentation has gone beyond this divide now such that many orthodox economists would deny any over-arching program among the areas which heterodox economists lump together as orthodox economics. ${ }^{4}$ This fragmentation is symptomatic of the incursion of some aspects of postmodernism into orthodox economics. The first element of postmodernism that is relevant here is the anti-humanist denial of the

\footnotetext{
${ }^{2}$ In methodological discussion this criterion was subject to a variety of interpretations: conforming to Popper's falsificationism or Lakatos's idea of the progressive research program, Friedman's instrumentalism or Samuelson's conventionalism etc. These are variants of positivism.

${ }^{3}$ Hahn (1973?) for example referred to the scaffolding of unrealistic assumptions which would eventually be removed.

${ }^{4}$ See for example Phelps's (1990) characterisation of the diversity within orthodox macroeconomics.
} 
scope for general government policy based on general theory. ${ }^{5}$ The second is the denial of any over-arching methodological principles, ${ }^{6}$ which has had the unfortunate consequence of being taken as support for inattention to methodology altogether, so that the emergence of fragmentation apparently has not provoked explicit reference to methodology. There has been an occasional explicit recognition of pluralism, eg by Blanchard and Fischer (1989) and an explicit welcoming of it by the Bank of England (1999). But there has been no attempt to establish the principles for theory choice within this pluralism, so that orthodox economics is open to the charge of incoherence.

From a heterodox perspective this apparent incoherence is ironic given the charge of incoherence laid against heterodox economics in the past (eg by Backhouse, 1988 and Caldwell, 1989 with respect to Post Keynesian economics). Indeed it could be argued that orthodox economics has embraced a pluralism which has been advocated by heterodox economists themselves. How we regard this fragmentation or pluralism, however, is a crucial issue for relations between the orthodoxy and heterodoxy, and the prospects for the progress of each.

Heterodox economists in fact continue to employ a critique of orthodox economics as a body of thought that is still in some sense unified. This reflects a recognition that there is still a common thread to orthodox economics which marks it out in distinction to heterodox economics and which governs theory selection. That thread is a methodological one that has ramifications for all forms of orthodox economics: mathematical formalism. ${ }^{7}$

The central role of mathematical formalism in orthodox economics constrains what is regarded as progress and thus profoundly influences relations between the orthodoxy and heterodoxy. Krugman (1998) for example argues that mathematical formalism is necessary for progress in economics. Backhouse (1998) also makes this argument, but discusses the problems caused by the form and scope of mathematics in modern economics: mathematics is necessary but not sufficient for progress. The scope of application of mathematical formalism is crucial since its subject matter is necessarily constrained to those factors which can be expressed mathematically (see Chick, 1998). For many orthodox economists, the scope of mathematical expression is taken to be so great that arguments which cannot be backed up, however loosely, by mathematical argument are seen either to be poorly expressed or not economics at all. Such a position legitimises the tendency for orthodox economists to ignore those elements of heterodox economics which are not expressed mathematically. The most pointed example of this is the Cambridge Controversies, where the argument revolved around the technical question of reswitching, although the Cambridge, England critique of the orthodoxy was much more substantial, but not mathematical. Their critique referred for example to the meaning of capital and the interpretation of the mathematical apparatus employed by the orthodoxy. By the same token, heterodox economics that draws (without mathematical expression) on history, sociology etc is often regarded as falling outside the boundary of economics. Of course, as McCloskey (first in 1983) has made so clear, all economists employ a range of informal methods

\footnotetext{
5 Thus Phelps (1990) for example characterises Keynes as modernist in contrast to the postmodernism of New Classicism.

${ }^{6}$ This aspect of postmodernism was made explicit for economics in McCloskey's (1983) influential statement on the rhetoric of economics.

${ }^{7}$ Hodgson (1999) also identifies formalism as the key distinguishing feature of orthodox economics.
} 
to express their theories. But the fact that the official discourse is mathematical provides a filtering device as to what is regarded as worthy of attention.

Further, mathematical formalism constrains orthodox economics in the form that its own development may take. It implicitly entails a particular view of the nature of the subject matter, the economy, as capable of being modelled as a closed system (see Chick, 1998). Thus, whatever the unofficial rhetoric, optimising agents are a feature common to all orthodox models, information is knowable (at least within a probability distribution), and so on. This corresponds to the positivist view of 'facts' as providing a testing ground for theory: atomistic pieces of information whose meaning is independent of the theory being tested, which are commensurate across contexts, and so on. Mathematical formalism and an obectivist understanding of 'the facts' are particularly conducive to identifying internal criteria for progress.

But, given this common strand of mathematical formalism, the pluralism of modern orthodox economics becomes rather worrying for the prospects for progress in orthodox economics, from its own perspective on progress. The great attraction of mathematics is that it makes apparently incommensurate material commensurate. In other words, from a mathematical formalist perspective, pluralism can only be regarded as a transitional state, until the parts are unified within a single, formal whole. This argument is made specifically by Blanchard and Fischer (1989: 505). If the current state of orthodox economics is to be regarded as progress, then, this can only be the case in a qualified sense. It is not clear therefore how the professed formalist methodology of the orthodoxy can sustain pluralism. Whether the pluralism of orthodox economics proceeds to the extent that it is no longer useful to draw a distinction between orthodox and heterodox economics therefore depends on a methodological rethink. As long as orthodox economics is anchored in mathematical formalism and all that entails, the distinction remains real, and problematic for the future of orthodox eocnomics.

\section{The Progress of Heterodox Economics}

Just as the defining feature of orthodox economics, I would suggest, is methodological, the same also is the case for heterodox economics. While we often focus on the diversity within heterodox economics, there is a common general methodological thread which is not always acknowledged, but which is crucial for any discussion of progress within the heterodoxy.

First, there is a Kuhnian understanding of the nature of science as being conducted within a set of scientific communities, each of which pursues its own paradigm (which ranges from a specific world view to a specific range of methods). While each community operates according to its own methodological principles (and thus criteria for progress), and indeed advocates these principles, there is a recognition that there will be other paradigms to which the advocacy is to be addressed. Progress within a Kuhnian framework proceeds on two fronts. One is progress based on normal science: puzzle-solving, both in terms of the internal framework and also in response to challenges to the framework in the form of new developments in the economy. This notion of progress coincides with the (internal) notion of progress in orthodox economics, as discussed above.

The second (external) notion of progress however refers to extraordinary science. Kuhn (1962) saw extraordinary science as not taking the principles of the ruling paradigm as given, but rather as challenging these principles and paving the way for replacing the ruling paradigm with another. Kuhn saw science as proceeding 
sequentially from one paradigm to another. For a social science this model is not appropriate; rather we can apply Kuhn's ideas to the different context of a continuing array of paradigms, one of which is dominant. Then extraordinary science has wider application. It refers not only to those working at the edges, as it were, of the dominant paradigm, but it also applies to much of the activities in competing paradigms which seek to supplant the dominant paradigm. The competing paradigms by definition question the principles of the dominant paradigm. That is why such a high proportion of work in heterodox economics is conducted at the level of principle: as criticism of the orthodox principles and putting forward alternatives. Progress in terms of extraordinary science consists in putting the orthodox paradigm on the defensive, and increasing the persuasive success of the alternatives. As Coats (1998) points out, much of the change within orthodox economics can be understood as addressing critiques raised within heterodox economics. But, to the extent that this constitutes successful paradigm defence, this is more a success for extraordinary science within the orthodox paradigm than for heterodox economics.

How far the orthodox paradigm can be successfully defended by means of adjustment in the face of critique depends on the degree to which this defence is seen to be coherent, and on the perceived capacity of the challenging paradigms to offer a satisfactory alternative. The alternative set of principles is one toward which the orthodox paradigm itself seems to be moving, ie some form of pluralism. But the difference is that the pluralism of heterodox economics is at the heart of the approach rather than a response to perceived inadequacies with prevailing principles. The pluralism of heterodox economics arises from an understanding of the nature of the economy as an open system. This contrasts with the orthodox understanding of the nature of the economy as being such that it can be modelled as a closed system. ${ }^{8}$ The Kuhnian understanding of science is an open-system approach to knowledge, such that no approach can justifiably lay claim to the truth. An open-system understanding of the nature of reality means that no one (closed-system) model can capture that reality. Some segments of that reality may be close enough to being a closed system, in a particular context, that a formal model may aid our understanding. But, if that system is only a segment of an open whole, in one context, the onus is on the economist to justify application of such a model to any context. Further, our understanding derived from the model may usefully be supplemented by knowledge arrived at using additional methods. By definition these methods and the formal mathematics of the model are not commensurate, otherwise they would constitute one, formal method. ${ }^{9}$

This approach is pluralist, but the term pluralism requires some further discussion, since it can be taken to mean quite different things (see further Dow, 1997b). Pure pluralism is the 'anything goes' approach. It is the dualistic denial of any one over-arching set of principles, replacing it with none. It is postmodern. It is also a denial of science. Those such as Blaug (1980) who attack pure relativism as the negation of science are quite right. If we have no principles for choosing one theory over another, or one method over another, or even for abstracting from reality in the first place, then reasoned knowledge cannot be built up. But it is a misunderstanding of Kuhn that he was advocating pure relativism. From a dualist perspective, that was seen as the only alternative to traditional science, proceeding according to an agreed set of principles. In fact Kuhn was pointing out that science proceeds according to

\footnotetext{
${ }^{8}$ This argument is most fully developed by Lawson (1997).

${ }^{9}$ This view of knowledge was developed by Keynes (1973).
} 
collections of principles agreed to by scientific communities, but open to question. Thus Kuhnian science is pluralist in the sense of allowing for a range of sets of principles, but it can only progress by means of normal science conducted by communities of scientists with shared principles. This is a modified form of pluralism, whereby principles are established, but may be questioned.

Heterodox economics has in common a set of principles that reflect the judgement that formalism is not the best way to proceed, while orthodox economists adopt formalist principles. Within heterodox economics, different paths are taken by different schools of thought which reflect different guiding principles for choosing theories and methods. I would argue that these different paths reflect different understandings of the nature of reality, which is an inevitable outcome of a starting position that reality is an open system and thus incapable of being understood categorically in terms of one modelling system. Each then have their own criteria for assessing progress in the sense of progress internal to the school of thought.

It is important for considering progress in the external sense of persuasiveness relative to the orthodoxy, therefore, that heterodox economics is methodologically coherent in a way which orthodox economics is not. The pluralism of orthodox economics is qualified by an adherence to formalism. But formalism is only justified by closed-system thought which can only accommodate pluralism as a temporary position.

But internal logic in practice is rarely sufficient for persuasion. Along with the Kuhnian view of science goes an awareness of the significance of persuasion for the relative progress of a paradigm. Persuasion is not a purely linguistic phenomenon, but extends to the sociological and the ideological. Hodgson (1999) elaborates on the general sociological make-up of the discipline, which heterodox economists are well aware of in their personal working lives. Appointments and publications are all crucial to the capacity to express ideas, far less persuade. Further, there is an asymmetry in that the orthodoxy has adopted a set of principles based on the internalist idea of the progress of science, with the best ideas naturally filtering to the surface, such that other ideas may justifiably be ignored. Since the expression of heterodox ideas generally does not conform to the orthodox principle of formalism, there is added justification.

So what can we conclude about the current state of heterodox economics and its prospects for progress? In terms of normal science, it proceeds apace. In numerical terms the communities of heterodox economists are getting larger. Along with this has gone the build-up of an institutional structure of textbooks, journals, associations and conferences. There is an impressive band of young scholars pushing ideas forward. In short the emphasis on extraordinary science which was evident in previous decades of reaction to the cementing of the orthodoxy in the post war years has given way to a growing emphasis on normal science.

But in the next section we concentrate on the much greater challenge, which is progress relative to orthodox economics. Has the new pluralism of orthodox economics allowed a successful defence of the orthodoxy to the detriment of heterodoxy, or has it opened the door to heterodoxy?

\section{A Strategy for Progress}

So far we have discussed the orthodoxy and heterodoxy in dualistic terms as being mutually exclusive. This has served to emphasise an argument that is important for any discussion as to the progress of heterodox economics, which is the common 
ground within heterodoxy. Often the focus is put on differences among heterodox economists, and for each heterodox paradigm to develop within separate institutional arrangements. Further, from the perspective of the orthodoxy, the apparent differences among the challengers makes it easier to dismiss the challenge. But the comparison drawn above between orthodoxy and heterodoxy implies that a further modification of the Kuhnian framework is required for economics. Not only may several paradigms co-exist, each with their own guiding principles, but some paradigms may be seen to have more in common than others. ${ }^{10}$ It has been argued that the guiding principle of orthodox economics is formalism. Heterodox paradigms share a rejection of formalism. While they then establish principles for theory and method choice (ie paradigms) which differ according to their particular views of the nature of the economy, they do hold this important principle in common. This lends legitimacy to the very idea of talking about heterodox economics as a recognisable whole. Further, I would argue that it is significant for considering a strategy for progress relative to orthodox economics.

However, the concept of paradigm, like any concept, is a formal device designed to capture something important, but unlikely to find a precise counterpart in reality. The concept of paradigm captures what may be regarded as the views of a 'representative' member of the paradigm. Many individual economists prefer not to be categorised and many can be seen to straddle more than one paradigm. Indeed it is arguable that episodes of notable development in economics have occurred as a direct result of connections being made across paradigms (see Loasby, 1991).

Given the shared open-system approach of the heterodox paradigms, such connections are to be expected, and examples of constructive connections are legion. It is connections across the orthodox-heterodox divide which are more contentious. Coats (1998) refers to change in the orthodoxy in directions which could be said to have been prompted by heterodox economics. Is it to continue to be the primary role of heterodox economics to prompt useful developments in the orthodoxy? Is this a sustainable basis for progress in orthodox economics? It could be argued that this defensive strategy has succeeded so far for orthodox economics and that there is no reason to doubt that it can continue indefinitely. But I would argue that there has been a qualitative change in the way in which heterodox ideas are being absorbed. While once they were absorbed by adjusting the assumptions in models designed to fit into a large general equilibrium system, now they are absorbed by piecemeal developments within a fragmented structure.

A notable recent example is the discussion of uncertainty in the design of monetary policy in the wake of the failure of the large closed-system macro models of the 1980s (see for example Goodhart, 1998). This discussion comes close to the (open-system) concept of true uncertainty as understood within heterodox economics, and could thus be regarded as a breakthrough for heterodox ideas among policymakers. The Bank of England's (1999) official account talks of combining different models and pieces of evidence on the basis of the 'judgement' of the Monetary Policy

\footnotetext{
10 One further possible configuration would be to consider the various schools of thought within heterodox economics as one paradigm, alongside the various subgroups in orthodox economics as another; the first is the open-system paradigm and the second the closed-system paradigm. But this would diminish the significance of the open-system approach allowing for a range of understandings of the nature of the economy (though agreeing that it is an open system), while the closed-system approach only allows one understanding because of the constraint to view human nature as expressible in mathematics.
} 
Committee. This raises all sorts of methodological issues about coherence with regard to the application of theory; for example, how compatible are models assuming fullyinformed rational economic agents with the uncertainty of the policy-maker? But the academic literature (on model uncertainty and robust control theory) which is responding to this development in applied economics, is forced back into a quantifiable version of uncertainty, where judgement and incommensurate forms of evidence have no role, clearly because of the requirements of formalism. Formalism thus puts significant constraints on the capacity of the orthodoxy to absorb heterodox ideas.

But these constraints could be the undoing of orthodox economics. The fact that the orthodox academic literature cannot provide a grounding for the design of monetary policy on the basis of uncertainty cannot hold back the fact that policy must be made. Similarly, the inattention of the orthodox literature to matters regarded by potential students as important (see Hodgson, 1999) such as economic institutions and economic processes, is right now contributing to weakening enrolment figures and falling regard among the general public.

The time would appear to be ripe for a challenge to the ruling paradigm: in Kuhnian terms there would appear to be the recipe for a crisis in orthodox economics. Just as the orthodox refusal to address the problem of unemployment in the 1930s paved the way for Keynes's ideas in the 1930s, could the same be possible in the new millennium?

This parallel makes clear the problem with challenging the orthodoxy in economics. There was not in fact a Keynesian revolution in the sense of an overthrow of the prevailing paradigm precisely because Keynes's methodological ideas were not absorbed along with his policy ideas. ${ }^{11}$ The neoclassical synthesis was a triumph for mathematical formalism, whereas Keynes had very explicitly made the case againstsuch an approach. As long as mathematical formalism remains the guiding principle of orthodox economics, heterodox economics cannot hope to supplant it.

Just as there are many economists straddling different heterodox paradigms, so there are many economists straddling the orthodox paradigm and heterodox economics. Many orthodox economists are well aware of the problems with orthodox economics, but hold back from the brink of proceeding along alternative lines. Partly this is due to a lack of awareness of what heterodox economics has to offer. But more importantly I would argue that the pervasiveness of the mathematical formalist criterion is what ultimately dissuades; even if more heterodox economics were accessible in mainstream sources, there tends to be an automatic filtering out of any non-mathematical argument which is not connected, however loosely, to a mathematical model. Thus for example formalism is generally taken to require that human action be portrayed mathematically. However many orthodox economists demur from the idea of rational economic man as capturing the essence of human nature, the requirement to produce some sort of mathematical account leads them right back to rational economic man.

Adding these considerations to the fact that the institutional power of orthodox economics is increasing with formal mechanisms for peer review, etc, paints a rather pessimistic picture of what might be made of what is otherwise a situation ripe for a revolution of ideas. But at least because they recognise the importance of sociological,

\footnotetext{
${ }^{11}$ Keynes did initiate a substantial new research program, with important implications for economic policy, but he did not succeed in his stated goal of revolutionising the way we think about economics.
} 
institutional and rhetorical devices for persuasion as being necessary accompaniments to logic, heterodox economists should be well-placed for designing a strategy for progress relative to the orthodoxy.

In keeping with the (qualified) pluralist heterodox view of the economy and of knowledge, what seems most appropriate is a (qualified) pluralist strategy. The main point behind what is suggested below is that it involves a range of approaches to be adopted simultaneously, rather than one exclusive strategy. In turn, this strategy would involve different heterodox economists pursuing one or more elements of the strategy. In other words, it would be perfectly reasonable for some to concentrate on some aspects of the strategy and others on other elements without any necessary problem of conflict. It is the essence of a pluralism qualified by the limitations imposed by a shared vision that different individuals may follow different routes towards the same goal. Indeed it is the capacity to follow different routes simultaneously (unified by the common goal) which is the strength of pluralism.

4.1 Normal Science. Since scientific revolutions require not only a successful critique but also a persuasive alternative, it is important for efforts to continue to be devoted to normal science within the heterodoxy, particularly (with a view to persuasion) addressed to questions of policy importance. It is particularly important to recognise the contribution being made by young heterodox economists, who have grown up in the awareness of an entrenched orthodoxy and in the knowledge of the heterodox critique, and who are taking forward heterodox ideas. Many are seeking synthesis among the different heterodox approaches. While some of the older heterodox economists have been able to publish in orthodox outlets, it has been particularly difficult for up-and-coming heterodox economists to do so. There is therefore very little scope for orthodox economists to be aware of their work and thus of the dynamic of heterodox research. It is therefore particularly important that young heterodox economists be given the chance to publish their work in heterodox journals. Further, in order to promote progress in the internal sense, it would be helpful for each heterodox paradigm to consider specifying more explicitly its core principles.

4.2 Extraordinary Science. At the same time as the development of heterodox paradigms, it is also important to engage in extraordinary science that explicitly addresses the different foundations of different paradigms. By focusing on the issue of mathematical formalism, heterodox economists can at the same time emphasise their own common ground while spelling out the source of the problems with orthodox economics. Successful persuasion on the question of foundations itself requires a range of strategies. One important strategy is to encourage a general awareness of foundations and why they matter. A major problem in communicating methodological ideas to orthodox economists is the widespread unwillingness to discuss methodology at all (see Lawson, 1994). A second strategy is to demonstrate what is possible beyond mathematical formalism. The reluctance of dissatisfied orthodox economists to leave formalism behind is a lack of conviction that the alternative is preferable. To some extent persuasion along these lines requires communicating with orthodox economists on their own ground, as a means of conveying ideas from heterodox economics. There are particular issues where orthodox economics has clearly been found wanting and where new ideas may be welcome, eg prediction of financial crises, where there is scope for explaining heterodox economists' concerns with a purely mathematical formalistic approach. 
4.3 Institutions. Persuasion requires more than good argument, however. We have seen how important the institutional structure of economics has been in cementing the dominance of the orthodoxy. Thought therefore needs to be given to the institutional structure within heterodox economics. The first implication of the discussion above is that heterodox economics has an important common ground. In terms of presenting heterodox economics in general (rather than any one heterodox paradigm in particular) as a worthy alternative to the orthodoxy, it is important to stress this commonality. Institutionally, this suggests that an umbrella organisation (like ICARE) is of tremendous importance, both for improving communications within heterodox economics, and for enhancing the outside image of heterodox economics. There is a strong argument for forming such umbrella groups nationally as well as internationally for the purposes of engaging in national academic politics (regarding coverage at national economics conferences, etc).

I suspect that most orthodox economists are genuinely unaware of the scale and dynamism of heterodox economics; mainstream publishing outlets are effectively barred to most on methodological grounds, and most heterodox economists are in a minority in any department. Most significant of all is probably the fact that, since heterodox economics falls outside the net of mathematical formalism, it is not even recognised as economics. Many heterodox economists have moved into the much more open new business-related disciplines. This could suggest a strategy of continuing to find an academic home elsewhere while orthodox economics withers under declining enrolments. But this strategy is not without its own dangers. Business schools have their own views about what type of subject economics is; in particular there is a danger of economics being regarded as a rather superficial input to business profitability. Second, many business schools' attitude to economics is tainted by a history determined by relations with orthodox economists, and heterodox economists are in danger of being tarred by the same brush.

4.4 Ideology and politics. Governments can be very influential in promoting particular sets of ideas. This is particularly the case in the UK, for example, where academic funding and standard-setting are highly centralised. The role of ideology, and the implications of institutional arrangements, are complex, but the upshot has been a situation which has tended to discourage the development of heterodox economics (see Hodgson, 1999).

One explanation is to see western governments as pro-capitalist and thus wary of heterodox economics. If this is the case, then heterodox economics must wait for more sympathetic ideological conditions. But in fact there is a wide range of ideologies represented in heterodox economics, and some have had direct influence on government - Hayek was influential in the Thatcher government, for example.

In terms of getting the attention of politicians who may have some role in shaping ideas, the important point about heterodox economics is not about ideology as such, but about the coherence of its methodology and its capacity to apply reason to a variety of sources of knowledge in order to design useful policy as a first priority, rather than being tied to mathematical formalism as the first priority. Within that overall methodological approach, there is a range of ideologies to choose from. Since policy relevance is one of the guiding principles of much of heterodox economics, heterodox economics could be much more persuasive in policy-making circles. It is 
important therefore that some heterodox economists pursue persuasion also along these lines.

4.6 The Notion of Heterodox Economics and Methodology. This set of strategies presumes a general perception of commonality among heterodox economists that may not currently exist. The argument here has depended crucially on heterodox schools of thought sharing an open-system approach to economics. It is my view that, if this commonality is not recognised, it is more a problem of perception than the actuality. Perhaps the very first stage towards broadly-based progress in heterodox economics as a whole is therefore to raise consciousness among heterodox economists themselves about their shared methodological foundations. There is already considerable communication between heterodox schools of thought, but institutional arrangements, like the umbrella organisations discussed under point $\mathbf{4 . 3}$ above, would be particularly important for enhancing mutual understanding.

\section{Conclusion}

The virtues of logical consistency, the importance of empirical testing and the capacity of the internal logic of economics to settle arguments have all been impressed upon heterodox economists by orthodox economists. It is thus ironic to see orthodox economics apparently succeeding by means of logical inconsistency, an unwillingness to submit to evidence, and the resort to sociological means (however unconsciously) to discourage heterodox economics. But, since heterodox economists understand the limits to mathematical formalism, we should accept this as normal and get on with the business of persuading those with doubts about orthodox economics that there are other possibilities. Since orthodox economics falls far short of its own professed standards we should not be discouraged if we too fall short. Rather we should focus on what is possible in economics. In fact, if it is indeed the case that heterodox economics is methodologically much more coherent than orthodox economics, we should be much more persuasive. Progress in heterodox economics is then more assured, on this solid foundation, than is orthodox economics.

\section{References}

Backhouse, R E (1988) The Value of Post Keynesian Economics. Bulletin of Economic Research 40(1), 35-41

Backhouse, R E (1998) If Mathematics Is Informal, Then Perhaps We Should Accept That Economics Must Be Informal Too. Economic Journal 108(451), 184858.

Bank of England (1999) Economic Models at the Bank of England. London: Bank of England.

Blanchard, O and Fischer, S (1989) Lectures in Macroeconomics. Cambridge, MA: MIT Press.

Blaug, M (1980) The Methodology of Economics. Cambridge: Cambridge University Press.

Caldwell, B J (1989) Post-Keynesian Methodology: An Assessment. Review of Political Economy,1(1). 
Coats, A W (1998) The Progress of Heterodox Economics. Mimeo.

Chick, V (1998) On Knowing One's Place: The Role of Formalism in Economics. Economic Journal 108(451), 1859-69.

Dow, S C (1990) Beyond Dualism. Cambridge Journal of Economics, 14(2).

Dow, S C (1997a) Mainstream Economic Methodology. Cambridge Journal of Economics 21(1), 73-94.

Dow, S C (1997b) Methodological Pluralism and Pluralism of Method, in A Salanti and E Screpanti (eds), Pluralism in Economics. Aldershot: Elgar, 89-99.

Goodhart, C A E (1998) Central Bankers and Uncertainty. Bank of England Quarterly Bulletin,

Hahn, F H (1973) The Winter of our Discontent. Economica, 40 (August).

Hahn, F H (1983) Money and Inflation. Cambridge, MA: MIT Press.

Hausman, D (1992) The Inexact and Separate Science of Economics. Cambridge: Cambridge University Press.

Hodgson, G (1999) Evolution and Institutions. Aldershot: Elgar.

Keynes, J M (1973) A Treatise on Probability. Collected Writings vol. VIII. London: Macmillan for the Royal Economic Society.

Kuhn, T S (1962) The Structure of Scientific Revolutions. Chicago: Chicago University Press.

Krugman, P (1998) Two Cheers for Formalism. Economic Journal 108(451),1829-36.

Lawson, T (1994) Why Are SO Many Economists So Opposed to Methodology? Journal of Economic Methodology, 1(1), 105-34.

Lawson, T (1997) Economics and Reality. London: Routledge.

Loasby, BJ (1991) Equilibrium and Evolution: An Exploration of Connecting Principles in Economics. Manchester: Manchester University Press.

McCloskey, D (1983) The Rhetoric of Economics. Journal of Economic Literature 21(June)

Phelps, E S (1990) Seven Schools of Thought in Macroeconomics. Oxford: Oxford University Press.

Weintraub, E R (1985) General Equilibrium Analysis. Cambridge: Cambridge University Press. 